\title{
Factors Associated with the Low Completion Rate of Pre-natal Consultations in a Health District in Senegal
}

\author{
Boubacar Gueye $^{1, \text { * }}$, Ndéye Marième Diagne ${ }^{2}$, Martial Coly Bop ${ }^{1}$, Alouine Badara Tall ${ }^{1}$, \\ Abdoul Aziz Ndiaye ${ }^{1}$, Ousseynou Ka ${ }^{1}$, Cheikh Tacko Diop ${ }^{1}$ \\ ${ }^{1}$ Health and Sustainable Development Department, Alouine Diop University, Bambeye, Senegal \\ ${ }^{2}$ Principal Hospital of Dakar, Dakar, Senegal
}

\section{Email address:}

boubsan2000@yahoo.fr (B. Gueye), yamaismael@yahoo.fr (N. M. Diagne), martialcoly.bop@uadb.edu.sn (M. C. Bop),

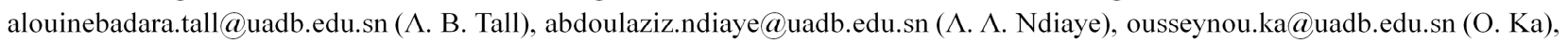
cheikhtacko.diop@uadb.edu.sn (C. T. Diop)

*Corresponding author

\section{To cite this article:}

Boubacar Gueye, Ndéye Marième Diagne, Martial Coly Bop, Alouine Badara Tall, Abdoul Aziz Ndiaye, Ousseynou Ka, Cheikh Tacko Diop. Factors Associated with the Low Completion Rate of Pre-natal Consultations in a Health District in Senegal. European Journal of Preventive Medicine. Vol. 8, No. 6, 2020, pp. 113-118. doi: 10.11648/j.ejpm.20200806.13

Received: November 10, 2020; Accepted: November 23, 2020; Published: December 4, 2020

\begin{abstract}
Introduction: Maternal-fetal and child morbidity and mortality is still a major public health problem despite all the progress made. It can be reduced significantly by proper monitoring of pregnancy through the 4 recommended pre-natal consultations (PNC). However, PNC completion rates remain low in sub-Saharan Africa. The Koki health district is no exception to this reality with $39 \%$ completion rate. The objective of this study is to determine the factors associated with PNC completion by pregnant women in order to make recommendations which aim to reduce maternal and fetal morbidity and mortality in the Koki health district in Senegal. Methodology: A cross-sectional descriptive study was conducted among 603 women who gave birth between 01/01/2017 and 31/12/2017 in the health district's area of responsibility. Two-stage cluster sampling was conducted. The first stage involved the selection of villages through a simple random draw. The second concerned the selection of concessions chosen by the bottle method. The number of clusters per Health Service Delivery Point (HSDP) was based on the number of expected pregnancies. Thus the survey consisted of 30 clusters of 20 women. All women meeting the criteria were selected from the concession. Data entry and analysis was done using Epi Info version 7.2.3.0. Results: The sample consisted of aged 26.15 years old average women, married, predominantly educated (52.75 per cent), and of Wolof ethnic group (66.6 per cent). More than $2 / 3$ of the women $(61.63 \%)$ were within $5 \mathrm{~km}$ of the health facilities. The majority of women (68\%) had their own income. Almost all women were satisfied with the reception (97.5\%) in the HSDP. Half of the women $(50.61 \%)$ had their first PNC in the first trimester of pregnancy. The PNC completion rate calculated with prenatal consultation booklet data is $30 \%$. The main factors having a statistically significant relationship with the low PNC completion rate are: age $\geq 30$ years, number of pregnancies $>3$, number of deliveries $>3$, distance between home and HSDP $\geq$ $5 \mathrm{~km}$, PNC high cost perception and lack of own income. Conclusion: The reasons for the low PNC completion rate are related to the obstetrical situation, geographical accessibility, but also the woman's financial situation. Achieving a satisfactory completion rate require not only a greater awareness and empowerment of women, but also accessibility to health facilities.
\end{abstract}

Keywords: Associated Factors, Pre-natal Consultations, Completion Rate, Senegal

\section{Introduction}

Mortality remains a concern in sub-Saharan Africa despite the progress made, with a ratio of 211 maternal deaths per 100,000 live births in 2017 , compared to 12 per 100,000 in developed countries [1]. In Senegal, in 2017 this rate was still high at 315 maternal deaths per 100,000 live births [2].

Much of the maternal-fetal and child morbidity and mortality could be prevented by proper pregnancy monitoring [3]. Antenatal care is defined as "the package of care that a woman receives during pregnancy to ensure that 
she and her newborn survive pregnancy and childbirth in good health" [3-6]. In high-income countries, almost all women receive at least $4 \mathrm{PNCs}$, unlike in low-income countries where only $40 \%$ of pregnant women had received the recommended 4 PNCs in 2015 [7].

In Senegal, the proportion of pregnant women who had at least 4 PNCs in 2017 is $57 \%$, whereas the national target is $75 \%$ [2]. With a PNC completion rate of $39 \%$ in 2017 , the Koki health district is below the national average (routine data).

In order to be effective, PNC must be performed at an early stage of pregnancy and continued with some regularity until delivery. In addition, only those who have started consultations on the first trimester of pregnancy will be able to complete PNC. The late use of PNC is therefore a limiting factor in the comprehensive monitoring of pregnancy and therefore a potential risk factor for maternal-fetal morbidity and mortality [8].

Many factors limit the use of adequate antenatal care services and contribute to the low PNC completion rate, resulting in increased maternal and infant morbidity and mortality due to failure to screen and manage risk factors early [9-12].

Thus, this study aims to identify the factors associated with the low PNC completion rate in Koki health district. It will provide recommendations to help reduce maternal-fetal and neonatal mortality in the Koki health district.

\section{Methodology}

This is a cross-sectional descriptive and analytical study conducted in the district from October $5^{\text {th }}$ to $11^{\text {th }} 2018$ on women who gave birth in the district health facilities in the period from January $1^{\text {st }}$ to December $31^{\text {th }}, 2017$.

Women who declined to participate in the study or who were absent at the time of the interviewer's visit were excluded from the study.

The sample size $(n=603)$ was calculated using the Schwartz formula.

The Health District is divided into 11 areas of responsibility, all of which were enrolled. The area of responsibility is defined by a number of villages corresponding to the HSDP polarization zone. Each zone was assigned a number of clusters proportional to the number of expected pregnancies. A two-stage sampling was carried out. The first stage involved a random drawing of clusters, and the second stage the drawing of concessions. Cluster selection was done by simple random draw without replacement. In total, we had 30 clusters of 20 women for the district area. Concession selection was determined by the bottle method.

WHO AFRO defines a quality PNC as the achievement of $4 \mathrm{PNC}$ at the recommended dates and performed by qualified personnel respecting clinical and para clinical examinations and preventive measures; the recommended dates of achievement are $\mathrm{PNC}_{1}: 1-3^{\text {rd }}$ month; $\mathrm{PNC}_{2}: 4-6^{\text {th }}$ month; $\mathrm{PNC}_{3}: 7-8^{\text {th }}$ month; $\mathrm{PNC}_{4}$ during the $9^{\text {th }}$ month.
The completion rate is the proportion of women who completed their 4 PNCs according to the standards on the number of women received $\mathrm{PNC}_{1}$.

The dependent variable in our study is the completion of antenatal consultations.

The independent variables are:

1. socio-demographic data: age, number of deliveries, number of pregnancies, female education, husband's education, marital status, ethnic group and PNC practice decision-maker;

2. data related to the use and accessibility of services: distance between home and the HSDP, PNCs performed, reception quality in the HSDP, woman's own income, and PNC cost perception.

The collection, which lasted 5 days, was done by a questionnaire filled during individual interviews and the examination of women's prenatal consultation booklet.

Socio-demographic data, and data related to the accessibility and use of health services are collected.

They were entered and analyzed using the Epi info version 7.2.3.0 software.

First, a univariate analysis was performed to describe the sample. In the second stage, an analytical study, in bivariate form, was conducted to study the links between the different variables and the dependent variable. The Fisher's exact test and the Chi2 test were used under the conditions of their applicability. The confidence interval was 95 per cent, and the difference was considered significant if $\mathrm{p}$-value was less than 0.05 .

The free and informed consent of surveyed women was sought beforehand. The confidentiality of the individual interview and data was scrupulously respected.

\section{Results}

At the end of data collection, 603 women were surveyed. However, it should be noted that among these women, only 487 had their pre-natal consultation booklets available and properly completed.

\subsection{Profile of the Study Population}

\subsubsection{Socio-demographic and Economic Data}

Table 1. Distribution of women surveyed according to socio-demographic data $(n=603)$

\begin{tabular}{lll}
\hline Variables & $\mathbf{n}$ & $\mathbf{\%}$ \\
\hline Age $\geq 30$ years & 187 & 31 \\
Number of pregnancies $>3$ & 245 & 40.6 \\
Number of deliveries $>3$ & 215 & 35.7 \\
Married & 603 & 100 \\
Ethnic Groups & & \\
Wolofs & 401 & 66.6 \\
Peulhs & 183 & 30.4 \\
Maures & 8 & 1 \\
Others & 11 & 2 \\
Uneducated women & 285 & 47.75 \\
Uneducated husbands & 217 & 36 \\
\hline
\end{tabular}

The age of the women ranged from 16 to 45 years with a 
mean of 26.15 years, a standard deviation of \pm 6.11 years, and a median at 25 years. The [15-29] age group represents $69 \%$ of the sample.

All of the women surveyed are married. Women with a number pregnancies $\leq 3$ and those with a number of deliveries $\leq 3$ are the most represented with proportions of $59.4 \%$ and $64.3 \%$ respectively. Women from the Wolof ethnic group represent $66.6 \%$ of the sample. Women are educated in $52.75 \%$ of cases and their husbands in $64 \%$ of cases (Table 1).

\subsubsection{Data on the Use and Accessibility of Services}

Women declare in $99.50 \%$ of cases (600 women) to have done at least one PNC. Most of them (81.16\%, or 487 women) have their pregnancy monitoring booklet available and informed. Only 250 women $(51.3 \%)$ had their first pre-natal consultation in the first trimester.

The exploitation of PNC's booklets revealed the following:

1. 250 women had a PNC between 1 - 3 months $\left(\mathrm{PNC}_{1}\right)$

2. 437 women between 4 - 6 months $\left(\mathrm{PNC}_{2}\right)$

3. 409 women between months $7-8\left(\mathrm{PNC}_{3}\right)$

4. 298 women in month $9\left(\mathrm{PNC}_{4}\right)$

5. 146 women completed all 4 PNCs within the recommended time frame (PNC completion).

6. This gives us a completion rate of $30 \%$.

Table 2. Distribution of women surveyed according to data on the use and accessibility of PNC services $(n=603)$.

\begin{tabular}{lll}
\hline Variables & $\mathbf{n}$ & $\mathbf{\%}$ \\
\hline Distance to HSDP $>5 \mathrm{~km}$ & 232 & 38.5 \\
Unsatisfactory reception & 15 & 2.5 \\
Lack of women's own income & 194 & 32 \\
PNC high cost perception & 154 & 25.5 \\
No access to PNC information & 171 & 28.4 \\
Women PNC practice decision-makers & 285 & 47.3 \\
\hline
\end{tabular}

In our study, $38.5 \%$ of women said they had traveled a distance of $5 \mathrm{~km}$ or more to access health facilities. Almost all women $(97.5 \%)$ were satisfied with the reception conditions (waiting time and conditions, confidentiality, quality of care, consultation schedule). The cost of PNC is estimated to be low in $74.5 \%$ of cases. Among the women surveyed, $68 \%$ have their own income from their activities.

Most of the women (71.64\%) reported having received information on the usefulness of PNC through various channels (discussion, radio, etc.). Most women (52.74\%) decide themselves when to start their PNC (Table 2).

\subsection{Results of the Analysis}

Table 3. Results of links between PNC completion and socio-demographic data $(n=487)$

\begin{tabular}{|c|c|c|c|}
\hline Variables & Number and \% of women who have not completed their PNC & Tests & P value \\
\hline \multicolumn{4}{|l|}{ Age } \\
\hline$<30$ years & $229(31 \%)$ & Fisher's Exact Test & $\mathrm{p}=0,0000$ \\
\hline$\geq 30$ years & $43(27.75 \%)$ & & \\
\hline \multicolumn{4}{|l|}{ Number of pregnancies } \\
\hline Number of pregnancies $\leq 3$ & $186(65.7 \%)$ & Fisher's Exact Test & $\mathrm{p}=0.01$ \\
\hline Number of pregnancies $>3$ & $155(76 \%)$ & & \\
\hline \multicolumn{4}{|l|}{ Number of deliveries } \\
\hline Number of deliveries $>3$ & $44(75.7 \%)$ & & \\
\hline \multicolumn{4}{|l|}{ Ethnic Groups } \\
\hline Wolofs & $224(68.3 \%)$ & $\chi_{\text {Pearson }}^{2} 1.928$ & $\mathrm{p}=0.58$ \\
\hline Peulhs & $104(73.24 \%)$ & & \\
\hline Maures & $4(66.6 \%)$ & & \\
\hline Others & $9(81.82 \%)$ & & \\
\hline \multicolumn{4}{|l|}{ Women's education } \\
\hline \multicolumn{4}{|l|}{ Husband's education } \\
\hline Educated husbands & $220(69 \%)$ & Fisher's Exact Test & $\mathrm{p}=0.53$ \\
\hline Uneducated husbands & $121(72 \%)$ & & \\
\hline
\end{tabular}

Non-completion of PNC has a statistically significant relationship $(\mathrm{p}<0.05)$ with certain elements of the socio-demographic profile: age $\geq 30$ years, number of deliveries $>3$ and number of pregnancies $>3$ (Table 3 ).

Table 4. Results of links between the completion of NPCs and data on the use and accessibility of NPC services ( $n=487$ )

\begin{tabular}{|c|c|c|c|}
\hline Variables & Number and \% of women who have not completed their PNC & Tests & P value \\
\hline \multicolumn{4}{|l|}{ Geographic accessibility } \\
\hline Distance to $\mathrm{HSDP} \geq 5 \mathrm{~km}$ & $137(82 \%)$ & Fisher's Exact Test & $\mathrm{p}=0.01$ \\
\hline Distance to $\mathrm{HSDP}<5 \mathrm{~km}$ & $204(63.75 \%)$ & & \\
\hline \multicolumn{4}{|l|}{ Reception } \\
\hline Not satisfactory & $6(54.5 \%)$ & Fisher's Exact Test & $\mathrm{p}=0.318$ \\
\hline Satisfactory & $355(70.4 \%)$ & & \\
\hline \multicolumn{4}{|l|}{ PNC cost Perception } \\
\hline
\end{tabular}




\begin{tabular}{|c|c|c|c|}
\hline Variables & Number and \% of women who have not completed their PNC & Tests & P value \\
\hline \multirow{2}{*}{\multicolumn{4}{|c|}{ Women's income }} \\
\hline & & & \\
\hline Lack of income & $255(73.5 \%)$ & Fisher's Exact Test & $\mathrm{p}=0.011$ \\
\hline Existence of income & $86(61.4 \%)$ & & \\
\hline \multicolumn{4}{|l|}{ PCN information access } \\
\hline No & $95(67.3 \%)$ & Fisher's Exact Test & $\mathrm{p}=0.45$ \\
\hline Yes & $246(71 \%)$ & & \\
\hline \multicolumn{4}{|l|}{ PNC practice decision-maker } \\
\hline Women & $184(70 \%)$ & Fisher's Exact Test & $\mathrm{p}=0.76$ \\
\hline Other (spouse, mother-in-law, etc.) & $157(70.7 \%)$ & & \\
\hline
\end{tabular}

Non-completion of PNC has a statistically significant relationship $(p<0.05)$ with certain data related to the use and accessibility of PNC services: distance between home and the HSDP $\geq 5 \mathrm{~km}$, high cost perception of PNC and the lack own income of pregnant women (Table 4).

\section{Discussions}

\subsection{Profile of the Study Population}

The socio-demographic profile of the pregnant women studied generally matches that of the population to which they belong.

The young age of the women can be explained by the presence of the strong Peulh community, known for their custom of early marriage. In addition, all the women are married. However, this finding was not made in other studies such as the one by Fame conducted in Mali in 2013, by Kandé in Senegal in 2016 and by Keita ${ }^{*}$ in Senegal in 2017 [10-12]. These differences could be explained by the sociocultural realities of the study area: Koki is an Islamized area with a very pronounced conservative religious practice (many religious families). This religious dimension is not compatible with motherhood outside of marriage. This phenomenon can also be explained by the fact that some pregnant women, out of modesty, present themselves as married thought they are not.

The predominant ethnic groups are Wolof and Fulani as in the general population.

Illiteracy (47.25\% of women) reveals the under-schooling of girls held at home for domestic activities or because of early marriage. This illiteracy is less significant among husbands (36\% of husbands); in general, men are better educated than women in the commune of Koki.

Moreover, the HSDPs are accessible (61.5\% of our sample live less than $5 \mathrm{~km}$ from a health facility). This can be explained by the fact that the health district is small with good coverage of health facilities (area: $931 \mathrm{~km}^{2}, 10$ health posts, and 1 health center).

The majority of women were satisfied $(97.5 \%)$ with the reception of health facilities. However, this finding was not found in several studies $[9,11,12]$. This may be due to social desirability bias, i.e., women want to give positive responses to assess HSDP and their managers, especially since the investigators belong to these structures.

A large proportion of them report having attended a discussion on the usefulness of PNCs. Indeed, many communication interventions are carried out by the health district on the subject of maternal health. Similar results were found in the studies by Kande ${ }^{*}$ and Keita ${ }^{*}[11,12]$.

In our series, women have a great deal of decision power over the practice of their PNC (52.7\%). An almost equivalent proportion of women $(51.3 \%)$ had their first PNC in the first trimester of pregnancy. It is reasonable to assume that the more decision-making power women have on the start of their $\mathrm{PNC}$, the earlier the $\mathrm{PNC}_{1}$ will be performed and the higher the completion rate will be.

The completion rate is intimately related to early PNC (realized in the first trimester) due to the method of calculation. The prerequisite for a good completion rate is first to have a high rate of $\mathrm{PNC}_{1}$. This issue has already been addressed by many studies [13-16]. The associated factors most frequently found for late PNC are: high age, high number of deliveries, illiteracy, geographical and financial inaccessibility $[10,12,15$, 16]. Several factors were also identified as affecting prenatal consultation center attendance and therefore PNC completion: factors related to geographic and financial accessibility were the most frequently cited [9-11]. However, other factors are found in the literature: the woman's marital status, monthly income, awareness of PNC, acceptance of early PNC by family and friends, and satisfaction $[11,12]$.

Only $51.6 \%$ of women make their first prenatal consultation in the first trimester. There are several reasons for this phenomenon: hidden pregnancy for fear of attracting the "evil eye", unwanted pregnancy, ignorance of their pregnancy, reluctance to see male care takers, etc. [15].

The majority of women $(89.7 \%)$ make their first prenatal consultation during the 2 nd trimester $\left(\mathrm{PNC}_{2}\right)$. At this stage the pregnancy is apparent and women are no longer hiding. This proportion of women gradually decreases to $83.9 \%$ in $\mathrm{PNC}_{3}$ and $61.2 \%$ in $\mathrm{PNC}_{4}$.

The PNC completion rate in our study is $30 \%$ below the national average of $57 \%$. This rate is lower than the administrative data which was $39 \%$ in 2017. This discrepancy was also found in the study conducted by Kandé $^{*}$ in the Medina Yoro Foula health district, which had a rate of $24.5 \%$ [11].

In fact, the survey data better reflects reality. Completion rate is usually calculated with routine data, which sometimes poses a problem of reliability. Our study is based on a representative sample of the population. 


\subsection{Factors Associated with the Completion of NPCS}

Women of age $\geq 30$ years old have a significantly low PNC completion rate $(p=0.00)$. These women usually have a great deal of experience in maternity and have very little respect for the recommendations of health care staff. In addition, they have little access to information.

The number of deliveries $>3$ and the number of pregnancies $>3$ significantly influence the non-completion of PNC ( $p=0.01$ and $p=0.04$ respectively). This finding was made by the study of Domingues* in 2013 in Brazil and Soultani $^{*}$ in 1993 in Monastir [13, 19]. These women, certainly older and with a lot of experience on maternity, neglect their pregnancy. In addition, they have less access to health information and are less receptive to sensitization. Younger women with less than 3 pregnancies and deliveries, on the other hand, are more respectful of their NPCs, perhaps because of their inexperience with motherhood.

Geographic inaccessibility (distance to the HSDP $>5 \mathrm{~km}$ ) of health facilities has a significant link with non-completion of PNC ( $p=0.00002)$. These same results are also observed in several studies conducted by Faye A et al. in 2014 in Kolda but also by Abdereman* in the same region in $2013[14,20]$. This is due to the fact that populations who are far from health facilities have difficulties in accessing them, especially in view of the socio-economic context.

Financial inaccessibility significantly influences the noncompletion of PNCs $(p=0.01)$. Thus, women without their own income may have difficulty getting to health facilities. Several studies have shown the role of the economic level on the use of health services for prenatal consultation. The study conducted in Benin in 2008 shows that the proportion of women who do not complete the program decreases when moving from low-income to high-income households [21]. This finding has also been made in other studies [20]. The same result was found by Kone* in Ivory Coast in 2006 [16]. This can be explained by the fact that access to care has a cost. The PNC high cost perception is significantly related to non-completion in our study $(\mathrm{p}=0.046)$. This is also part of the influence of economic factors on the use of maternal health services. Analysis of the value of monthly household income with completion would be more relevant, but this was not done because most of the women surveyed did not know their monthly household income.

In summary, our study was able to highlight the factors related to the low PNC completion rate which are: age $\geq 30$ years old, number of pregnancies $>3$, number of deliveries $>$ 3 , distance between home and the HSDP $\geq 5 \mathrm{~km}$, PNC high cost perception and lack of own income.

On the other hand, reception at the level of health facilities, access to information on PNC, women's autonomy in decision-making on the practice of PNC do not seem to have a significant influence on the completion of PNC.

\subsection{Limitations and Strengths of the Study}

The limitations of the study are that not all women not only did not have their booklets, but even among those who did, some were not filled out. As a result, the completion rate was not measured among all surveyed women who had their booklets. The other limitation found was the social desirability bias related to the fact that there are declarative data that may not reflect reality.

The strength of this work is the assessment of completion that was measured directly from the booklet, but also the power of the study from a fairly representative sample of the general population.

\section{Recommendations}

These different social, demographic, accessibility and health service utilization factors related to non-completion of PNCs are often intertwined. A multisectoral and multidisciplinary approach to interventions is therefore necessary to resolve the problem of non-completion of PNCs.

The following recommendations are proposed:

1. Improve the accessibility of PNC by promoting the advanced PNC strategy at the district level;

2. Develop innovative actions such as refocused PNC. It reinforces interpersonal communication, allowing the patient to know the timing and interest of PNC. This allows them to remain loyal to the PNC until delivery;

3. Improve women's empowerment by developing income-generating activities within their associations;

4. Develop health education messages focusing on the importance of completing PNCs, targeting women of at-risk age, multi-gestational and multiparous women.

\section{Conclusions}

Maternal-fetal and infant morbidity and mortality is still high in most developing countries and particularly in Senegal. It can be reduced by monitoring pregnancy from conception to delivery and even after delivery. Hence the interest in promoting regular antenatal consultations, which beyond medical examinations are opportunities to build trust between the woman and the health care provider, but also to personalize health promotion messages. Good PNC services link the woman and her family to the formal health system, increase the chances of having a skilled care taker at delivery and reinforce good health throughout the life cycle. Inadequate care at this point breaks an essential link in the continuum of care with all its damaging consequences. It is therefore important to improve the geographical accessibility of care and to have innovative communication approaches for women of reproductive age.

\section{References}

[1] World Health Organization. (2019). Evolution of maternal mortality 2000 - 2017: WHO, UNICEF, UNFPA, World Bank Group and United Nations Population Division estimates: orientation summary. 2019; https://apps.who.int/iris/handle/10665/332962. License: CC BY-NC-SA 3.0 IGO. 
[2] National Agency for Statistics and Demography (ANSD) [Senegal], and ICF. 2018. Senegal: Demographic and Continuous Health Survey (EDS-Continue 2017). Rockville, Maryland, USA: ANSD and ICF.

[3] Chalmers B, Mangiaterra V, Porter R. WHO principles of perinatal care: the essential antenatal, perinatal, and postpartum care course. Birth. 2001; 28 (3): 202-7. doi: 10.1046/j.1523-536x.2001.00202.x.

[4] Di Mario, Simona \& Basevi, Vittorio \& Gori, Gianfranco \& Spettoli, Daniela. (2005). What is the effectiveness of antenatal care? (Supplement). WHO Regional Office for Europe's Health Evidence Network (HEN), 2005.

[5] Cisse T, Ngoma ST, Saloyl M, Tall Diaw C, Diadhiou F. Neonatal mortality monitoring at the CHU in Dakar (Sénégal): Cahier Santé 1997; 7 (2): 109-12.

[6] Diagne A. Evaluation of the Quality of Pre-Natal Consultation Practice in the Louga District. [CES Public Health Memory (Epidemiology, Statistical Bio and Computer Science)] Senegal; Cheikh Anta Diop University, Dakar: Institute of Health and Development, 1995; 21 p.

[7] Maternal Mortality. Aide-mémoire No. 348. World Health Organization. November 2016: Accessible to: www.who.int/mediacentre/factsheets/fs348/fr/.

[8] Bakouan E et al. Determining the low proportion of pregnant women seen at first prenatal consultation. [Health Attaché in Epidemiology Diploma Memory]. Burkina Faso: National School of Public Health; 2011.

[9] Faye A, Faye M, Ba IO, Ndiaye P, Tal-Dia A, Factors determining the place of delivery in women who have benefited from at least a pre-natal consultation in a sanitary structure (Senegal), Revue d'Epidémiologie et Santé Publique. Oct 2010; Flight 58 (5) ISSN 0398-7620, http://dx.doi.org/10.1016/j.respe.2010.05.004

(http://www.sciencedirect.com/science/article/pii/S03987620(10)00424-4).

[10] Fame TA, Fournier P, Ridde V. Qualitative study on the causes of first delay and their impact on the morbidity of obstetric emergencies: The case of the beautiful escapes of the district of Diemal (Mali). [Community Health Master Memory]. Canada; University of Montreal: Faculty of Medicine, 2013. Available at: https://papyrus.bib.umontreal.ca/xmlui/bitstream/handle/1866/ 8737/Fame_Thiaba_2012_memoire.pdf?sequence=2\&isAllow $\mathrm{ed}=\mathrm{y}$.

[11] Kande B and the Study of Determinants of Completion Rate of Pre-Natal Consultations in the Health District of Medina
Yoro Foulah in 2016. [Public Health Memory]. Senegal: Cheikh Anta Diop University in Dakar. Institute of Health and Development. 2016.

[12] Keita IM et al. Study of the determinants of completion of prenatal consultation in the Goudomp Health District (Sédhiou/Senegal). [Public Health Memory]. Senegal. Sheik Anta Diop University of Dakar. Institute of Health and Development. 2017.

[13] Soltani MS, Bchir A, Souissi M, Brahim H. Prenatal surveillance and determinants of prenatal monitoring in the Monastir Health District in Tunisia. Med Too. March 1993; 53 (2): 201- 4, PMID: 8412589.

[14] Tall AB, Faye A, Ndiaye AA, Gaye A, Gueye B, and al. Community-Based Maternal and Neonatal Health Services in Kolda and Sedhiou districts of Senegal. Global Journal of Health Science. 2018; 10 (3): 90-110 ISSN 1916-9736 EISSN 1916-9744 Published by Canadian Center of Science and Education doi: 10.5539/gjhs.v10n3p90 URL: https://doi.org/10.5539/gjhs.v10n3p90.

[15] Ndiaye P, Tal Dia A, Diedhiou A, Diey EHL, Dione DA. Sociocultural determinants of the delay of the $1^{\text {st }}$ pre-natal consultation in a health district in Senegal. Santé Publique 2005; 17 (4), 531-8.

[16] Koné PA, Rivard M. Poverty and socio-cultural determinants of maternal health services in Ivory Coast. Rev Epidemiol Santé Publique 2006; 54 (6): 485-95. https://doi.org/10.1016/S0398-7620(06)76748-7.

[17] Vangeenderhuysen C, De Sardan JPO, Moumouni A, Souley A. About some obstetric practices in Niger. Cahier Santé 1998; 8 (4): 265-8.

[18] Ndiaye P, Diallo I, Wone I, Fall C. A new tool to help medical decision-making in the fight against maternal mortality: "the dystocia risk score". Cahier Santé 2001; 11: 133-8.

[19] Domingues $\mathrm{M}$ et al. Access and use of antenatal care services in the unified health system of the city of Rio de Janeiro, Brazil. Rev. Bras. Epidemiol 2013; 16 (4).

[20] Abderemane A, Faye A, Seck, Tall-Dia A. Study of the determinants of first prenatal consultation in the first trimester in women who gave birth from February 2013 to January 2014 in the Kolda region. [Master's thesis on public health 2014] Senegal; Cheikh Anta Diop University, Dakar: Institute of Health and Development. 2014.

[21] Dakpahossou B et al. Determinants of the irregularity in prenatal care in rural Benin. [Statistical Engineering Diploma Memory]. Benin. University of Abomey-Calavi (UAC). 2008. 